\title{
Mind the Gap! Making Stronger Connections between Hate Crime Policy and Scholarship
}

\begin{abstract}
With hostility and prejudice continuing to pose complex challenges for societies across the world, developments in hate crime scholarship and policy have facilitated a greater prioritization, improved understanding and collective action amongst a range of different actors, including law-makers and enforcers, non-governmental organisations, activists and 'ordinary' citizens. Despite this progress however, our collective responses to hate crime have been undermined by a disconnected approach to scholarship and policy.

This article focuses on a series of problems which are created and reinforced through such an approach. This includes the limited reach of hate crime scholarship, and specifically the perception that academic theorising is often too detached from the everyday realities confronting those who respond to - or live with - the consequences of hate crime in the 'real world'. Equally problematic is policy which is not empirically-driven or linked to academic knowledge, or which is based on tokenistic, cynical or 'tick-box' foundations. The article draws from these faultlines to underline the symbiotic relationship between hate crime scholarship and policy-formation: one where policyformation needs academic substance to be fit for purpose; and where scholarship needs to inform policy to have any lasting 'real-world' value to responses to hate crime.
\end{abstract}

Key words: Hate crime; policy; victimization; 'difference'; targeted hostility

\section{Introduction}

The term 'hate crime' has become increasingly familiar in recent years. With problems of bigotry continuing to pose complex challenges for societies across the world, hate crime is now an internationally-used expression; one that has the capacity to transcend differences in interpretation in order to promote a collective awareness of the harms of hate amongst a range of different actors, be they law-makers, law-enforcers, non-governmental organisations (NGOs), scholars, students, activists or 'ordinary' citizens. It remains a contentious term, with its conceptual, moral and legal basis continuing to be a perennial source of conjecture. However, most commentators would agree that hate crimes spawn a particular set of harms which distinguish them from other types of crime. These are summarised by the Office for Democratic Institutions and Human Rights (2009) who describe the multiple layers of damage caused by hate crimes in terms of their violation of human 
rights and equality between members of society; the greater psychological injury and increased feelings of vulnerability inflicted upon the individual victim; the sense of fear and intimidation transmitted to the wider community to whom the victim 'belongs'; and the security and public order problems that ensue from the widening of potentially explosive social tensions.

To some extent these problems have been acknowledged through a greater prioritisation and improved understanding of issues at an academic and policy level. For instance, to avoid becoming side-tracked by the now familiar conceptual ambiguities of hate crime (see, inter alia, Jacobs and Potter, 1999; Hall, 2013; Chakraborti and Garland, 2015) Iganski (2008) refers to the merits of thinking of hate crime as both a policy and a scholarly domain: the first domain where elements of the political and criminal justice systems have converged through a succession of progressive social movements and campaigns to combat bigotry in its various guises; and the second where scholars ostensibly from diverse fields of study but united in their focus upon the synergies and intersections between different forms of discriminatory violence - apply their empirical knowledge to inform effective interventions. Indeed, the success of the conference whose themes inspired this special issue - the inaugural conference of the International Network for Hate Studies ${ }^{1}$ (INHS) - is testimony to the progress made within both domains. Exchanging ideas to advance hate crime research and policy with a large, multi-disciplinary and multi-national collection of delegates was a truly heartening experience, especially for those of us who have seen hate crime-themed events flounder in the past as a result of narrow audiences and narrow perspectives.

And yet despite this progress, I would argue that much more can be done to foster stronger connections between the domains of hate crime policy and scholarship. Without seeking to underplay the encouraging developments that many of my co-contributors refer to in this special issue, this article focuses on a series of problems which are created and reinforced through a disconnected approach to scholarship and policy-formation; an approach which has seen academics and practitioners operate on separate lines without having sufficient regard for the benefits of working in tandem. Three particular problems are examined: the disconnects between academic work, 'real-world' work and lived experiences; the implementation gaps between policy interventions and empirically-driven knowledge; and the dangers of tokenistic 'tick-box' responses to hate crime. The acknowledgement of these faultlines should not be seen as cause for despair, but rather as a yardstick by which we can measure effective collaborative working and responses to hate crime.

\section{Aren't we already connected?}


Before exploring 'disconnects' between, within and beyond academic and policy domains, it is worth pausing briefly to consider the value of existing 'connections'. Perhaps more than ever before, those working in these domains are bonded by a set of shared values when it comes to defining hate crime, and this is a significant leap forward from the protracted debates over its conceptual basis which, though necessary in part, have overshadowed other more practical challenges. Whilst there is no single, universally accepted definition of hate crime or international framework of protected characteristics, academics and policy-makers now tend to think in broadly similar directions, for the most part at least, when conceiving of hate crimes as acts of hostility (not simply hate and not necessarily criminal acts alone) directed towards a person's identity or 'difference' (see, inter alia, Chakraborti 2014; College of Policing, 2014; Hall, 2013; Chakraborti and Garland, 2012; Garland, 2012).

This increased sense of conceptual consistency has been accompanied and informed by legislative progress. Within the United Kingdom alone we have seen a series of laws introduced by successive governments covering different forms of hate crime, as well as a wealth of criminal justice policy and guidance and relentless campaign group activism relating to various spheres of targeted victimization (Mason-Bish, 2010). These developments have been mirrored across the world, with the United States, Canada, Australia and many states across Western and Eastern Europe deploying their own sets of laws which treat hate crimes as specific offences which carry higher penalties than comparable non-hate offences, or as offences which have provision for sentence uplift if there is sufficient evidence of hostility or bias motivation. Again, the scope and implementation of these laws may vary, but their very existence - allied with the tireless work in this arena undertaken by NGOs and lobbyists - has significant value.

Equally, the volume of theoretical and empirical developments in the hate crime field over recent years has helped to create a significantly more nuanced picture of these multi-layered and complex offences. Put simply, we now know much more about hate crime than ever before: more about the groups of people who suffer hate crime and who perpetrate hate crime; more about the nature, extent and impact of victimization; more about the factors behind the selection of victims; and more about the effectiveness, or otherwise, of different interventions. These are just some of the areas where our knowledge has grown, and the continuing development of hate crime studies will invariably lead to further empirically-informed advances. But as well as knowing much more we are talking to each other much more about hate crime, as illustrated by the welcome growth in the numbers of multi-agency partnerships, practitioner and academic networks, conferences, seminars, symposia and other information-sharing fora that attract attendees from different sectors of work 
and from different parts of the world. This thirst for knowledge and information exchange has shaped thinking across a number of academic disciplines, including criminology, psychology, sociology, history, political science and legal studies; within statutory, voluntary and private sectors; and from senior figures in political and criminal justice spheres 'down' to activists, campaigners and community volunteers working at a grassroots level (Garland, 2014). Without question and as alluded to above, this has led to tangible progress in a number of respects, and examples of good practice are now well documented (see, inter alia, Chakraborti and Garland, 2014).

So why then the deliberately gloomy tone of this article? Why, at a time when the hate crime movement has achieved so much and is more 'connected' than ever before, should we be concerned about faultlines? Feeling gloomy in the light of such progress might seem somewhat counterintuitive to some, and the reservations expressed here do not detract from the overall sense of optimism I share with fellow contributors when it comes to contemporary developments. But at the same time, it is important to question the impact of this progress, not so much in terms of what has been achieved but more with regard to what could be achieved given the growth of interest and resource attached to hate crime. Specifically, my concerns relate to the way in which our knowledge creation, partnership working and information-sharing can at times resemble little more than hot air or a self-sustaining industry to many of those directly affected by hate crime whose experiences, needs and expectations are not addressed in any meaningful way by developments in hate crime policy and scholarship. These concerns are explored in the sections that follow.

\section{Problem \#1: Disconnects between academic work, 'real world' work and lived experiences}

A contributory factor to some of the progress described above has been a rise in joined up working between national government, local authorities, criminal justice agencies and other service providers to improve the way that hate crimes are dealt with. Within the context of the UK for instance, the relevance of a holistic approach was acknowledged in the 2012 Government Action Plan whose recommendations around preventing hate crime and increasing reporting and access to support gave emphasis to the importance of locally administered responses involving all criminal justice agencies as well as other professionals, voluntary organisations and communities (HM Government, 2012). This joined-up working may sometimes involve academic input but it is here that cracks begin to emerge within our collective responses to hate crime, with academics and practitioners often working within separate cloisters without having sufficient regard for the benefits of operating in tandem. 
A polarised approach to hate crime scholarship and policy formation creates and reinforces a series of significant problems. One of these relates to the perceived usefulness (or otherwise) of hate crime scholarship, and specifically the perception that academic theorising is often too complex, too ethereal and too detached from the everyday realities confronting those who deal with hate crime cases in the 'real world'. This criticism could obviously be extended to other areas of academia more generally but it is a feeling that practitioners are often quick to share with me and with others working within the field of hate crime. It is also evident within the different ways in which hate crime is conceived of within the two domains: whereas scholars tend to see hate crime as an elusive social construct contingent upon a complex set of defining characteristics which they regard as central to its commission, practitioners often adopt a much more straightforward stance for practical reasons which requires few of the machinations evident within academic interpretations. As Giannasi (2014: 35) wryly observes when referring to practitioners' frustrations with academic theorising:

'If you put four academics in a room and asked them to define hate crime they would emerge days later with five different definitions'.

If hate crime scholarship is to have a sustained impact upon policy and practice then academic theorising cannot be developed in any meaningful sense without one eye on the practical application of those theoretical ideas. This is crucial not just to policy formation but in the wider context of maximising the real-life value of scholarship and policy to those countless numbers of victims whose experiences of hate crime go unnoticed. My recent research conducted alongside Jon Garland and Stevie-Jade Hardy provides a vivid illustration of this point. Over the course of this UKbased two-year study of hate crime victimization we heard from nearly 1,500 victims of hate crime, the majority of whom had little or no familiarity with the term 'hate crime', despite having suffered what most scholars and practitioners would automatically class as hate crime victimization on multiple (or in some cases, on countless) occasions (Chakraborti, Garland and Hardy, 2014) ${ }^{2}$. For these victims, experiences of hate crime were normalised as an everyday, unwanted but routine reality of being 'different' rather than being seen as an act of victimization that should be reported. Moreover, many such victims found themselves based on the margins of 'mainstream' society, where knowledge of hate crime policy and associated publicity campaigns and reporting structures is invariably lower; where people are likely to feel less comfortable about sharing their experiences through official channels; and where the sense of bitterness, alienation and resentment that often fuel acts of hate crime is likely to be felt all the more as a result of prevailing economic conditions (see also Gadd, 2009). 
To discover that so few hate crime victims were familiar with the terminology that we - as scholars, policy-makers, practitioners and activists - take for granted was one of several disturbing realities that became apparent during the life of this research study. Equally problematic was the fact that several hundred of the victims who shared their experiences of targeted violence with us belonged to groups who have tended to be excluded from, or peripheral to, conventional hate crime frameworks. Whether targeted because of their 'alternative' appearance or lifestyle, their mental illhealth, their asylum seeker or refugee status or their gender identity (to name just some examples) these are groups of people who each have very different sets of identity characteristics and yet who share a form of 'difference' that gives rise to repeated acts of hostility. Such acts included faeces and fireworks being shoved through letterboxes, being harassed in person and through social networking sites, being exploited and humiliated, having car windows repeatedly smashed in, being beaten up, glassed and hospitalised. Some, albeit a small minority, of these 'marginal' hate crime victims had attempted to report their experiences to the police or to another support agency such as their local authority or housing association, but few felt as though their experiences had been taken seriously and fewer still would report again (Chakraborti, Garland and Hardy, 2014).

In both contexts, these are people for whom hate crime is much more than simply a thorny conceptual challenge. Freedom from cruelty, inhumane treatment and persecution are fundamental human rights and equality issues, and the failure to protect people from such behaviour has lifechanging consequences, particularly for those who lack the power of class or language, the privilege of advocacy groups and support networks, or the bargaining clout of political, economic or social mobility. Irrespective of any improvements made to reporting and recording structures or to the quality of criminal agency responses, in reality many victims are still denied access to support, either by virtue of not knowing what a hate crime is or how to access support, or because they are not 'obvious' hate crime victims immediately recognisable to frontline practitioners. As such they remain disconnected from the activism, policy-making and theorising going on around them despite our collective endeavours to 'make a difference'.

\section{Problem \#2: Implementation gaps between policy interventions and empirically driven knowledge}

If the value of academic theorising becomes more evident when it connects with 'real-world' hate crime responses and experiences, then equally the value of policy interventions is clearer when such interventions are grounded in scholarly evidence. This raises a further challenge that will be familiar to many readers: policy which is not empirically-driven or based upon academic knowledge is less likely to be effective. Grimshaw and Jefferson's (1987) influential work on police policy and practice 6 
refers to the implementation gaps (between what is supposed to happen and what actually happens) which can arise when policing decisions are guided by operational common sense and discretion rather than the requirements of law and managerial supervision. A similar argument could be used to account for implementation gaps in the hate crime environment wherever policy-making is not informed by academic knowledge. Good practice needs to be informed by good policy, which in turn needs to be informed by good scholarship. Of course these latter two factors do not in themselves guarantee good practice as the dangers of other issues such as occupational bias, the misapplication of discretion, the (un)availability of resources and wilful or unwitting neglect still remain. Nonetheless, the likelihood of correct decisions being taken is far higher with the other two building blocks in place (Chakraborti, 2014).

The problem posed by these implementation gaps can be understood through reference to the hate crime 'triangle' that Joanna Perry (2014) uses to describe the interactive process of connecting different spheres of work (see also her article in this special issue). At one point of the triangle we have activists and civil society organisations who evidence and construct the problem of targeted violence, with law makers at a second point responding by passing laws and tasking policy makers with their implementation. The triangle is completed by scholars who, for Perry, 'provide an intellectual space to help both policy makers and activists examine the consequences of conceptualising violence through the prism of 'hate' or 'bias', and evaluate the impact and effectiveness of established policies' (2014: 76). Whilst interaction within and between each of the points of this triangle can provide a platform for effective practice, in reality the triangle can become severely skewed. For instance, Perry outlines the difficulties confronting civil society organisations who within some political systems lack the resources to adequately monitor hate crime and the power to shape policy makers' opinions about its relevance or prevalence. Similarly, the international reach and appeal of academic work may be limited by scholars having conducted limited or no research in particular contexts, and/or such work being seen as irrelevant or peripheral to policy formation further afield. As a consequence, responses to hate crime can be ill-informed without the input of civil society or the academy, and fall short through a lack of evidenced policy making.

Perhaps most worryingly, an absence of synergy between these spheres of work can create a disjuncture between what hate crime victims want and what policy-makers think they want. This point becomes clear when we consider the way in which expressions of hate have been criminalised through the introduction of various legislative provisions. Although the scope and implementation of these provisions vary from state to state, the value of hate crime laws and their enforcement can be 
significant, whether in terms of their capacity to express our collective condemnation of prejudice; to send a declaratory message to offenders; to convey a message of support to victims and stigmatised communities; to build confidence in the criminal justice system within some of the more disaffected and vulnerable members of society; and to acknowledge the additional harm caused by hate offences (for further discussion see, inter alia, Chakraborti and Garland, 2015; Walters, 2014a; ODIHR, 2009; Iganski, 2008). Effective legislation and enforcement is clearly important, both for individual freedoms and security and for cohesive communities.

But yet at the same time, the needs of hate crime victims are not always addressed through the conventional punitive approach. Williams and Tregidga (2013) describe the gap between victimcentred reporting mechanisms and evidence-driven criminal justice prosecution processes which can leave victims - and in particular vulnerable victims of persistent 'low-level' hate incidents frustrated and additionally traumatised by the absence of stringent evidential proof required for prosecution. Similarly, the research described previously (Chakraborti, Garland and Hardy, 2014) has challenged prevailing assumptions about hate crime victims' inclinations for enhanced prison sentences by revealing an overwhelming preference - shared by victims of different types of violent and non-violent hate crime and from different communities, ages and backgrounds - for the use of educational programmes and restorative interventions as a more effective route to challenging underlying prejudices and preventing future offending.

For several years now the benefits of restorative approaches to hate crime have become increasingly relevant as scholars have begun to highlight the shortcomings of exclusively punitive responses. As Hall (2013) notes, prisons have limited deterrent value, offer limited opportunity for rehabilitative programmes and can be 'hotbeds' for prejudice, intolerance and hate group activity and recruitment (see also Gerstenfeld, 2013; Blazak, 2009). Walters (2014b) too has shown that the punishment and labelling of offenders as 'hate offenders' does little to challenge hate-motivated behaviours and equally little to support the healing of hate victims - beyond perhaps appeasing a visceral desire for an offender to receive his 'just deserts' - whereas restorative approaches offer a form of dialogue which can help to break down the fears, stereotypes and prejudices which give rise to hate crimes. However, with mounting evidence to suggest that victims themselves - and not 'merely' academics or practitioners - are calling for alternative interventions, the policy drift towards punitive-oriented 'solutions' in isolation becomes all the more questionable. Whilst there are promising signs of change in the way in which responses to hate crime are becoming less prescriptive (Iganski, 2014; Perry and Ryan Dyck, 2014), the preceding discussion underlines just how important it is to frame policy interventions in line with empirical evidence. 


\section{Problem \#3: Tokenistic, 'tick box' responses}

We have seen how conceptual ideas which do not connect with 'real-world' requirements, and policy responses which are not rooted in academic evidence, can create problems for the sustainability of hate crime interventions. These faultlines can also breed a sense of complacency within different domains that can undermine the credibility of hate crime work. Many readers will be familiar with, and frustrated by, those more sceptical voices which see the field of hate crime as resembling little more than an 'industry' where the term is used tokenistically, politically or cynically by organisations and individuals as a buzzword de jour or as a box to tick. In reality, these claims have little substance in a world where the collective endeavours of practitioners, researchers, activists and other campaigners are as necessary now as they ever have been in the fight against hate and prejudice. However, to silence such claims we must do all we can to create effective policies and to communicate knowledge. For instance, the improved understanding of disability hate crime that has emerged as a result of recent studies has not fully translated to the policy domain where problems of flawed multi-agency working, lip service amongst statutory organisations and failures to protect victims of disablist violence are still evident (Roulstone and Mason-Bish, 2013; Equality and Human Rights Commission 2012; Quarmby, 2011). Similar contentions could be made with regard to many other strands of hate crime, and particularly that suffered by some of the more marginalised members of society such as trans men and women, Gypsies, Travellers and the Roma, and asylum seekers and refugees, to name just some (James, 2014; Blair Woods and Herman, 2014; Burnett, 2012). These failings can lead to charges of tokenism and can quickly undo any sense of progress.

But so too can our failures to use the term hate crime judiciously or with any sense of purpose. To cite one example, I, like other contributors to this special edition, have been heartened by the increasing numbers of regional, national and international hate crime events held over recent years, but can recall too many instances where the subject matter has had only tenuous links to our field and has offered scant opportunity for delegates to learn and share relevant insights; or where the term has been interpreted far too narrowly or literally, thereby reinforcing the marginalisation of non-monitored strands of hate crime; or where such meetings and events have been used as 'talking shops' by practitioners or academics rather than as springboards for more meaningful dialogue and action within and between both domains. Consequently, and perhaps unfairly, this can create a damaging impression of separatism - or worse still of bandwagon-jumping - within the field of hate crime, and does little to bridge the gap between scholarship and policy. 
For the most part these kinds of problems will stem from a lack of clear thinking, a perceived shortage of time or a desire to find 'quick-fix' solutions, as opposed to any sense of deliberate neglect or oversight. However, the impact of these problems upon hate crime victims' perceptions and lived realities can be significant. Let me again draw from my recent research to illustrate this point (Chakraborti, Garland and Hardy, 2014). Leicester, the site for that research, is a city that has a proud reputation for celebrating its rich diversity ${ }^{3}$, and at face value has a robust set of processes in place to challenge hate crime via an extensive range of multi-agency partnerships, hate crime awareness campaigns, third-party reporting centres and community engagement strategies. However, having listened to hundreds of hate crime victims express grave reservations about these processes, we began to question their robustness. As noted earlier, most victims were completely unaware of the term 'hate crime' despite the growth of local and national awareness campaigns; barely any knew that they could report online or at venues like their local library or community centre; and the majority were highly critical of the mechanisms in place to support victims of crime and to reduce levels of prejudice (for a more detailed discussion, see Chakraborti, Garland and Hardy, 2014). Moreover, whether through their continued reliance upon self-appointed community leaders who are commonly out of touch with the breadth of concerns within their communities, or through an inability to see beyond reported cases of hate crime, many of the practitioners entrusted with delivering services to these victims were oblivious of the extent, nature and wider consequences of problems on their doorstep.

As such, we were confronted by a landscape where victims were unaware of available services; where service providers were unaware of victims and their problems; and yet perversely, where existing structures to combat hate crime were, prima facie, extensive, well represented and widely praised within the region and beyond. These kinds of anomalies are not at all unique, and the disconnect between agency and victims' perceptions of policy responses will invariably impact upon levels of take up and confidence in the effectiveness of those responses. However, if such disconnects remain unchallenged they will have other dangerous implications, not least with respect to the ongoing lack of meaningful engagement beyond self-styled community leaders; the ongoing problem of under-reporting amongst many groups of hate crime victims; and the ongoing marginalisation of vulnerable victims.

\section{Conclusions}

The concerns described in preceding passages are not designed to be unduly alarmist or to belittle progress made within academic and policy domains. Rather, they are illustrative of the fact that 10 
relationships between hate crime scholarship and policy-formation are symbiotic: policy-formation needs academic substance in order to be fit for purpose; and scholarship needs to inform policy in order to have any lasting 'real-world' value to responses to hate crime. Whilst there are faultlines between the two domains, we should also acknowledge that important work is being done to harness links between scholarship and policy, or to create what Garland (2014: 261) describes as 'a thaw in relations between researchers, policy makers and practitioners which has prompted a number of progressive programmes that have made a practical difference 'on the ground". This has helped hate crime interventions to transcend, at least in part, the kinds of divisions which have seen those outside the academy judge academic work as little more than high-brow intellectualism with little resonance to the practicalities and pressures of their own work, and those within the academy devalue the relevance of working outside of their 'ivory towers' (Giannasi, 2014; Garland, 2014).

Some of the more successful routes to harnessing such links have given emphasis to the development of practical toolkits, training and creative resources. One recent example comes from the Leicester Centre for Hate Studies, whose programme of Continuing Professional Development (CPD) workshops uses the lessons learnt from domestic and international research to provide practitioners with evidence-based training on hate crime perpetration, prevention and victimisation (Leicester Centre for Hate Studies, 2015). Crucially, these workshops draw from academic evidence, policy guidance and, perhaps most importantly, victim testimonies to engage practitioners from different sectors and varying levels of seniority. Creating channels of communication with different audiences has also been a key priority of the Sophie Lancaster Foundation, whose ongoing engagement with schools, universities, prisons and criminal justice agencies has enabled this small campaigning organisation to stimulate debates on the intolerance of 'difference' and to shape the way in which a number of English police forces record acts of hostility towards 'alternatives' (Garland, 2014b). The use of creative outputs - including animation, short films, social media, performance and digital content - has been pivotal to the engagement strategies deployed by both the Leicester Centre for Hate Studies and the Sophie Lancaster Foundation, and have played a similarly important role in humanising 'difference' within other contexts (see, inter alia, CAMHS, 2015; Perry and Ryan Dyck, 2014; Stonewall, 2010).

These are just some examples of how gaps between the academic and policy domains can be bridged through dialogue, knowledge exchange and meaningful intervention (for further examples see Chakraborti and Garland, 2014; Hall et al., 2014). However, while many within the hate crime field have moved beyond the indifference, or mutual enmity even, that has tarnished progressive alliances between these domains, this article has identified a series of long-standing and inter- 
connected problems which pose challenges to the efficacy of intra- and inter-domain working, and more importantly to the 'real-life' value of this working to those who are victims of hate crime. Whether in terms of the disconnects between hate crime interventions and hate crime experiences, the implementation gaps between different spheres of work, or charges of perceived or actual tokenism, these are problems which demand far greater reflection.

But above all else, and lest we need more reason to scrutinise the value of our work, we must not lose sight of the sheer numbers of people falling victim to hate crime. Most reliable measures suggest that levels of hate crime remain disturbingly high: recent sweeps of the Crime Survey for England and Wales, for instance, indicate that approximately 278,000 hate crime incidents are committed every year, a figure which is more than six times higher than corresponding policerecorded figures (Home Office, 2013). Similarly, contemporary studies of hate crime victimization across the world give little room for optimism when it comes to believing that the volume of hate crime, or its impact, is any less significant than at any time in the recent past (see, inter alia, Asquith, 2014; Corb, 2014; Chakraborti, Garland and Hardy, 2014; Williams and Trediga, 2013; European Union Agency for Fundamental Rights, 2013). Ultimately then, and despite our good intentions, improved knowledge and flurry of policy-making, the fact remains that hundreds of thousands of people are still subjected to hate offences every year, many on a regular basis. Whilst this grim reality does not invalidate our efforts, it should remind us not to become complacent.

\section{References}

Asquith, N. (2014) 'A Governance of Denial: Hate Crime in Australia and New Zealand', in N. Hall, A.

Corb, P. Giannasi and J. Grieve (eds) (2014) The Routledge International Handbook on Hate Crime, London: Routledge, pp. 174-189.

Blair Woods, J. and Herman, J. (2014) 'Anti-Transgender Hate Crime', in N. Hall, A. Corb, P. Giannasi and J. Grieve (eds) (2014) The Routledge International Handbook on Hate Crime, London: Routledge, pp. 278-288.

Blazak, R. (2009) 'The Prison Hate Machine', Criminology and Public Policy, 8 (3): 633-40.

Burnett, J. (2012) 'After Lawrence: Racial Violence and Policing in the UK', Race and Class, 54 (1): 91 98.

Child and Adolescant Mental Health Services (CAMHS) (2015) Freak! Mental Health Hate Crime Awareness Film, available at https://www.youtube.com/watch?v=Kuak8OD0bQE 
Chakraborti, N. (2014) 'Framing the Boundaries of Hate Crime' in N. Hall, A. Corb, P. Giannasi and J. Grieve (eds) (2014) The Routledge International Handbook on Hate Crime, London: Routledge, pp. 163-173.

Chakraborti, N. and Garland, J. (2015) Hate Crime: Impacts, Causes and Consequences (2 ${ }^{\text {nd }}$ edition), London: Sage.

Chakraborti, N. and Garland, J. (eds) Responding to Hate Crime: The Case for Connecting Policy and Research, Bristol: The Policy Press.

Chakraborti, N. and Garland, J. (2012) 'Reconceptualising Hate Crime Victimization through the Lens of Vulnerability and 'Difference', Theoretical Criminology, 16 (4): 499-514.

Chakraborti, N. Garland, J. and Hardy, S. (2014) The Leicester Hate Crime Project: Findings and Conclusions, Leicester: University of Leicester.

College of Policing (2014) Hate Crime Operational Guidance, Coventry: College of Policing.

Corb, A. (2014) 'Hate and Hate Crime in Canada', in N. Hall, A. Corb, P. Giannasi and J. Grieve (eds) (2014) The Routledge International Handbook on Hate Crime, London: Routledge, pp. 278-288.

Equality and Human Rights Commission (2012) Out in the Open. Tackling Disability-Related Harassment: A Manifesto for Change, Manchester: Equality and Human Rights Commission.

European Union Agency for Fundamental Rights (FRA) (2013) European Union Lesbian, Gay, Bisexual and Transgender Survey. Luxembourg: Publications Office of the European Union.

Gadd, D. (2009) 'Aggravating Racism and Elusive Motivation', British Journal of Criminology, 49 (6): 755-771.

Garland, J. (2014a) 'Conclusions' in N. Chakraborti and J. Garland (eds) Responding to Hate Crime: The Case for Connecting Policy and Research, Bristol: The Policy Press, 259-267.

Garland, J. (2014b) 'Reshaping Hate Crime Policy and Practice: Lessons from a Grassroots Campaign. An Interview with Sylvia Lancaster, Founder of the Sophie Lancaster Foundation' in N. Chakraborti and J. Garland (eds) Responding to Hate Crime: The Case for Connecting Policy and Research, Bristol: The Policy Press, 39-53.

Garland, J. (2012) 'Difficulties in Defining Hate Crime Victimization', International Review of Victimology, 18 (1): 25-37.

Gerstenfeld, P.B. (2013) Hate Crimes: Causes, Controls and Controversies ( $3^{\text {rd }}$ edition), London: Sage. 13 
Giannasi, P. (2014) 'Academia from a Practitioner's Perspective: A Reflection on the Changes in the Relationship between Academia, Policing and Government in a Hate Crime Context', in N. Chakraborti and J. Garland (eds) Responding to Hate Crime: The Case for Connecting Policy and Research, Bristol: The Policy Press, 27-38.

Grimshaw, R. and Jefferson, T. (1987) Interpreting Policework: Policy and Practice in Forms of Beat Policing, London: Allen and Unwin.

Hall, N. (2013) Hate Crime (2 ${ }^{\text {nd }}$ edition), Cullompton: Willan.

Hall, N., Corb, A., Giannasi, P. and Grieve, J. (eds) (2014) The Routledge International Handbook on Hate Crime, London: Routledge.

HM Government (2012) Challenge It, Report It, Stop It: The Government's Plan to Tackle Hate Crime, London: HM Government.

Home Office (with Office for National Statistics and Ministry of Justice) (2013) An Overview of Hate Crime in England and Wales, London: Home Office, Office for National Statistics and Ministry of Justice.

Iganski, P., with Ainsworth, K., Geraghty, L., Lagou, S. and Patel, N. (2014) 'Understanding How 'Hate' Hurts: A Case Study of Working with Offenders and Potential Offenders', in N. Chakraborti and J. Garland (eds) Responding to Hate Crime: The Case for Connecting Policy and Research, Bristol: The Policy Press, pp. 231-242.

Iganski, P. (2008) 'Hate Crime' and the City, Bristol: The Policy Press.

Jacobs, J. and Potter, K. (1998) Hate Crimes: Criminal Law and Identity Politics, Oxford: Oxford University Press.

James, Z. (2014) 'Hate Crimes against Gypsies, Travellers and Roma in Europe', in N. Hall, A. Corb, P. Giannasi and J. Grieve (eds) (2014) The Routledge International Handbook on Hate Crime, London: Routledge, pp. 237-248.

The Leicester Centre for Hate Studies (2015) Continuing Professional Development Services, available at http://www2.le.ac.uk/departments/criminology/hate/professional

Mason-Bish, H. (2010) 'Future Challenges for Hate Crime Policy: Lessons from the Past', in N. Chakraborti (ed.) Hate Crime: Concepts, Policy, Future Directions, London: Routledge, 58-77.

Office for Democratic Institutions and Human Rights (ODIHR) (2009) Hate Crime Laws: A Practical Guide, Warsaw: ODIHR. 
Perry, B. and Dyck, D.R. (2014) 'Courage in the Face of Hate: a Curricular Resource for Confronting Anti-LGBTQ Violence' in N. Chakraborti and J. Garland (eds) Responding to Hate Crime: The Case for Connecting Policy and Research, Bristol: The Policy Press, 185-197.

Perry, J. (2014) 'Evidencing the Case for Hate Crime', in N. Chakraborti and J. Garland (eds) Responding to Hate Crime: The Case for Connecting Policy and Research, Bristol: The Policy Press, 71-83.

Quarmby, K. (2011) Scapegoat: Why We Are Failing Disabled People, London: Portobello Books.

Roulstone, A. and Mason-Bish, H. (eds) (2013) Disability, Hate Crime and Violence, London: Routledge.

Stonewall (2010) FIT, The Movie, available at

http://www.stonewall.org.uk/at school/education for all/quick links/education resources/fit/4 036.asp

Walters, M. (2014a) 'Conceptualizing 'Hostility' for Hate Crime Law: Minding 'the Minutiae' when Interpreting Section 28(1)(a) of the Crime and Disorder Act 1998', Oxford Journal of Legal Studies, 34 (1): 47-74.

Walters, M. (2014c) Hate Crime and Restorative Justice: Exploring Causes, Repairing Harms, Oxford: Oxford University Press.

Williams, M. and Tregidga, J. (2013) All Wales Hate Crime Research Project: Research Overview and Executive Summary, Cardiff: Race Equality First.

\footnotetext{
${ }^{1}$ Set up in 2013 the International Network for Hate Studies is a cross-jurisdictional and interdisciplinary organisation that aims to facilitate the exchange of knowledge about the study of hate and hate crime. Further information about the Network can be found at http://www.internationalhatestudies.com/

${ }^{2}$ This research referred to here was funded by the Economic and Social Research Council (Grant number ES/J008109/1) and was conducted between September 2012 and September 2014. Further information
} 


about the research, its methodology and findings is available at
http://www2.le.ac.uk/departments/criminology/research/current-projects/hate-crime/our-reports-1

3 Leicester is located at the heart of the East Midlands of England and has a population of approximately 330,000 according to most recent Census data (Office for National Statistics, 2011). Leicester residents hail from over 50 countries from across the globe, making the city one of the most ethnically and culturally diverse places in the UK, and somewhere that is commonly depicted as a successful model of multiculturalism both nationally and internationally. 